\title{
Studies on electrical conductivity and dielectric behaviour of PVdF-HFP-PMMA-NaI polymer blend electrolyte
}

\author{
S K TRIPATHI* ${ }^{*}$ ASHISH GUPTA and MANJU KUMARI ${ }^{\dagger}$ \\ Department of Physics, Jaypee University of Engineering and Technology (JUET), Raghogarh, Guna 473 226, India \\ ${ }^{\dagger}$ Department of Chemistry, Viva Institute of Technology, Shirgaon, Virar (E) 401 303, India
}

MS received 4 October 2011; revised 17 January 2012

\begin{abstract}
Polymer blend electrolytes composed of poly(vinylidene fluoride-co-hexafluoro-propylene), poly(methyl methacrylate) and 1.0 M NaI as salt have been synthesized using solution caste technique by varying the PVdF(HFP)-PMMA blend concentration ratio systematically. A.c. impedance studies were performed to evaluate the ionic conductivity of the polymer electrolyte films. The highest ionic conductivity at room temperature for [PVdF(HFP)-PMMA(4:1)](20 wt\%) - [NaI (1.0 M)](80 wt\%) system is found to be $1.67 \times 10^{-2} \mathrm{~S} \mathrm{~cm}^{-1}$. XRD studies reveal complete complexation of the salt in the polymeric blend systems. The temperature dependence conductivity has been performed in the range of 303-373 $\mathrm{K}$ and it is observed that it obeys the Arrhenius behaviour. It has been observed that the dielectric constant, $\varepsilon_{\mathrm{r}}$ and dielectric loss, $\varepsilon_{\mathrm{i}}$, increases with temperature in the lower frequency region and is almost negligible in the higher frequency region. This behaviour can be explained on the basis of electrode polarization effects. Plot of real part, $M_{\mathrm{r}}$ and imaginary part, $M_{\mathrm{i}}$ vs frequency indicates that the systems are predominantly ionic conductors. The phenomenon suggests a plurality of relaxation mechanism.
\end{abstract}

Keywords. Polymer blend electrolytes; PVdF(HFP)-PMMA-NaI; impedance studies.

\section{Introduction}

The conducting polymer electrolytes have been intensely interesting to physicists, chemists and engineers because of their fundamental physical properties and potential application in various electrochemical devices such as fuel cells, supercapacitor, sensors and display devices (Gray 1991). The development of polymer electrolytes has gone through three stages which are dry solid-state polymers, gel/plasticizer polymer electrolytes systems and composite polymer electrolytes system.

The first category of solid polymer electrolytes e.g. PEO based electrolyte system, shows very low ambient temperature conductivities of the order of $10^{-8} \mathrm{~S} \mathrm{~cm}^{-1}$ (Fenton et al 1973).

The second category of polymer electrolytes is known as gel polymer electrolytes or plasticized polymer electrolytes which consists of both the properties of liquid and solid phases in the same electrolytes system. Combination of both properties i.e. the cohesive properties of solid and the diffusive properties of liquids give unique characteristics of the gel to find various important applications including polymer electrolytes (Bruce and Gray 1995).

Third category of polymer electrolytes are composite electrolytes. These are new categories of multiphase solid systems in which two or more materials are mixed together

\footnotetext{
*Author for correspondence (sktripathi16@yahoo.com)
}

to achieve improvement in its mechanical, thermal stability and high ionic conductivity of the polymer electrolytes. The polymer blending is one of the most promising and feasible ways to improve the ionic conductivity, flexibility and mechanical strength of the composite systems. When two or more polymers give rise to a homogeneous mixture, miscible or compatible blend is formed in which one polymer is adopted to absorb the electrolytes active species while another remains as an undissolved inert second phase providing toughness to the polymer electrolytes films (Berthier et al 1989).

Many lithium ion based blend polymer electrolyte systems have been studied and reported in the literature. Among them are PVdF-HFP/PMMA (Lee and Park 2000), PVAc/PVdFHFP (Ulaganathan and Rajendran 2010), PVAc/PMMA (Rajendran et al 2010), PVC/PEO (Ramesh et al 2007), PVAc/PMMA (Baskaran et al 2004, 2006), PVA/PMMA (Rajendran and Sivakumar 2008), PVdF/PVC (Rajendran et al 2008), PVC/PMMA (Lee and Park 2000), PVdFHFP/PAN (Subramania et al 2006) and PVdF-HFP/PVAc (Choi et al 2001), PVDF-HFP/PEG (Lee et al 2003) blend based electrolytes system. These electrolytes are of great importance, because of its possible application in different energy storage/conversion devices, particularly in rechargeable batteries. Many research articles are available which incorporates sodium ion in its polymeric system for its application as electrolyte materials in sodium batteries (Wang et al 2007; Kim et al 2008). There also exists some sodium ion conducting polymer electrolytes based on poly-ethylene-oxide (PEO) and poly-propylene- 
oxide (PPO) complexed with $\mathrm{NaSCN}, \mathrm{NaI}, \mathrm{NaClO}_{3}, \mathrm{NaPF}_{4}$, $\mathrm{NaYF}_{4}, \mathrm{NaCF}_{3} \mathrm{SO}_{4}, \mathrm{NaNO}_{3}$ and $\mathrm{NaClO}_{4}$ (Sreepathi Rao et al 1995; Sreekanth et al 1999) which has been reported for its application as electrolyte materials in sodium batteries. Usually, low-evaporation solvents, like organic solvents, ethylene carbonate, propylene carbonate (PC), dimethyl carbonate (DEC), dimethyl farmamide (DMF), dimethyl carbonate (DMC) etc are used as plasticizers (Agrawal and Pandey 2008). The plasticizers should possess some specific properties like an increase in conductivity, increases of amorphous regions, a wide redox stability, ionic mobility, behaviour of cells etc (Sheldon et al 1989; Michael et al 1997).

In the present study, PVdF-HFP/PMMA polymer blend electrolytes were prepared by incorporating $\mathrm{NaI}$ as the doping salt. PVdF-HFP has been chosen because of its appealing properties. It has high dielectric constant, $\varepsilon^{\prime}$, of 8.4 reported by Lee and Park (2000) which occurred in two phases (amorphous and crystalline). Amorphous phase enhances higher ionic conduction in the system meanwhile crystalline phase provides strong mechanical support to the polymer electrolytes (Stephan et al 2006; Hwang et al 2007). In order to improve the ionic conductivity, PMMA was used because it has good amorphous and compatible nature. It is also known that PMMA gels were found to have better interfacial properties for electrodes and provides good mechanical properties with another polymer. Poly (methyl methacrylate) (PMMA) was first reported by Iijima et al (1985). Sodium is much more abundant and lower priced than lithium and the softness of sodium metal promotes the stability of electrode electrolytes interface in solid state ionic devices (Hunter and Ingram 1984).

Combining all of the above said properties of polymers and salt, we have chosen PVdF(HFP)-PMMA-NaI based blend system for our present investigations.

\section{Experimental}

\subsection{Sample preparation}

The polymer blend electrolyte has been prepared by using polymers, PVdF-HFP with an average molecular weight of 4,00,000 (Aldrich), PMMA with an average molecular weight of 1,30,000 (Aldrich) and inorganic salt, NaI (Merck) which has been used as such without further purification. DMF ( $N-N$ dimethyl formamide) has been used as the solvent (Deepa et al 2002). The polymer films were developed by using the well known solution cast techniques. The mixture of polymers and doping salt in suitable amounts were stirred continuously with a magnetic stirrer for $10 \mathrm{~h}$ at a temperature of $60{ }^{\circ} \mathrm{C}$ until homogenous solutions were obtained. The solutions were poured into glass petri dishes and left to dry at room temperature to form a film for about 35-40 days. The films were kept in desiccators for further drying.

\subsection{Conductivity measurement}

To study the conductivity behaviour of the polymer electrolytes, impedance spectroscopy was performed using LCR HiTESTER [HIOKI, 3522-50, Japan]. The samples were cut into a proper size and sandwiched between two stainless steel electrodes. The conductivity $(\sigma)$ was calculated using the following equation

$$
\sigma=t / R_{\mathrm{b}} A
$$

where $t$ is the thickness of the electrolyte, $A$ the electrolytes contact area and $R_{\mathrm{b}}$ the bulk resistance which was obtained from the plots of real impedance $Z^{\prime}$ against imaginary impedance $Z^{\prime \prime}$. The mathematical equation of impedance can be written as

$$
Z^{*}=Z^{\prime}+i Z^{\prime \prime}
$$

Using the impedance data, the dielectric constant $\left(\varepsilon^{*}\right)$, electrical modulus $\left(M^{*}\right)$ was obtained using the following equations.

$$
\begin{aligned}
& \varepsilon^{\prime}(\omega)=Z^{\prime \prime} / \omega C_{0}\left(Z^{\prime 2}+Z^{\prime \prime 2}\right), \\
& \varepsilon^{\prime \prime}(\omega)=Z^{\prime} / \omega C_{0}\left(Z^{\prime 2}+Z^{\prime \prime 2}\right), \\
& M^{\prime}(\omega)=\varepsilon^{\prime} /\left(\varepsilon^{\prime 2}+\varepsilon^{\prime \prime 2}\right), \\
& M^{\prime \prime}(\omega)=\varepsilon^{\prime \prime} /\left(\varepsilon^{\prime 2}+\varepsilon^{\prime \prime 2}\right),
\end{aligned}
$$

where $\varepsilon_{0}$ is vacuum space permittivity, $\varepsilon^{\prime}$ the dielectric loss and $\omega$ the $2 \pi f, f$ is the frequency in $\mathrm{Hz}, C_{0}=\varepsilon_{0} A / t, A$ is the electrode-electrolyte contact area and $t$ the thickness of electrolyte.

$\mathrm{X}$-ray diffraction patterns were recorded at room temperature by Bruker Advance (D8) X-ray diffractometer with $\mathrm{Cu} \mathrm{K} \alpha$ radiation over a bragg angle $(2 \theta)$ range of $10^{\circ}-60^{\circ}$.

\section{Results and discussion}

\section{$3.1 X$-ray diffraction studies}

In order to examine the influence of PMMA contents on the semicrystalline structure of PVdF-HFP based blend polymer electrolyte system, the X-ray diffraction patterns of pure NaI salt, PVdF-HFP, PMMA, PVdF-HFP/PMMA blend polymer films recast from its DMF, PVdF-HFP/PMMA/NaI blend polymer electrolytes film are shown in figure 1. XRD pattern of the PVdF-HFP film shows typical characteristic of a semicrystalline microstructure i.e. the co-existence of mixed crystalline and amorphous regions with predominant peaks at $2 \theta=20^{\circ}$ and $38^{\circ}$ (Saikia and Kumar 2004). Further the absence of sharp Bragg peaks and the presence of broader peaks in XRD pattern of PMMA shows predominant amorphous nature of the PMMA polymer (figure 1c). It is observed that when PVdF-HFP is blended with PMMA, 


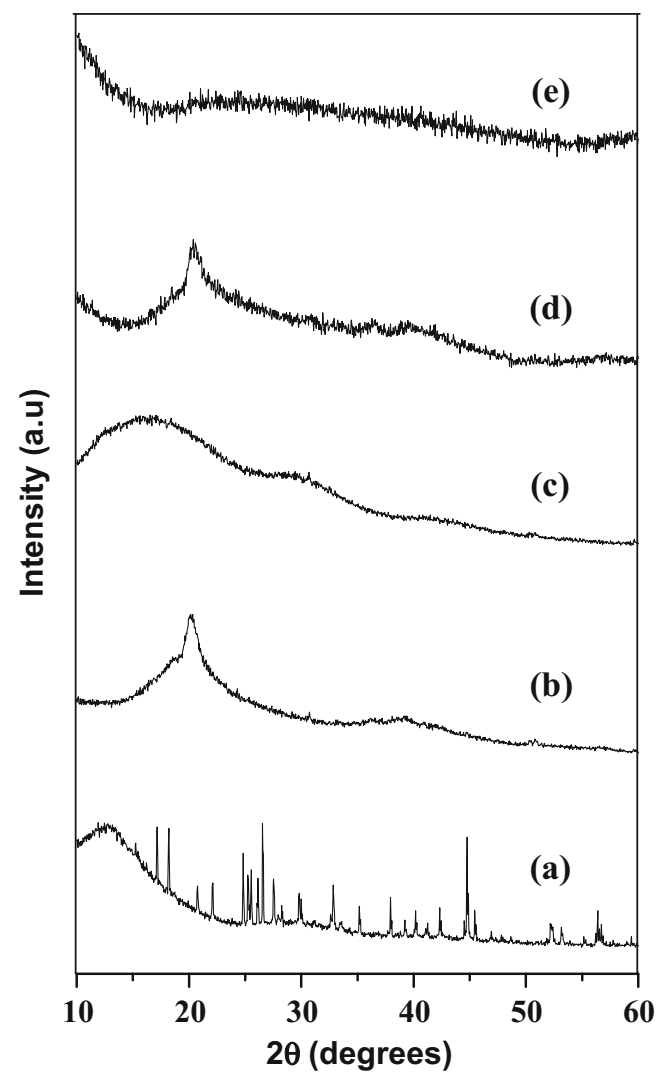

Figure 1. XRD spectra of (a) pure NaI, (b) $\mathrm{PVdF}(\mathrm{HFP})$ film, (c) PMMA film, (d) PVdF(HFP)/PMMA optimized film and (e) $\mathrm{PVdF}(\mathrm{HFP}) / \mathrm{PMMA} / \mathrm{NaI}$ optimized film.

no additional peak in the blend system appears, but only the intensity of crystalline peak of the PVdF-HFP decreases (figure 1d), suggesting that the amorphicity of the blend system increases to some extent (Leo et al 2002). Finally, it is observed that by mixing of NaI with PVdF-HFP/PMMA blend, the NaI and PVdF-HFP peaks get completely disappeared in the optimized composition of polymer blend electrolytes (figure 1e). This indicates that the salts, NaI most likely blends with the PVdF-HFP/PMMA polymer blend at the molecular level and it gives a clear indication of complexation of the salt in the polymer blend system.

\subsection{Polymer concentration dependence conductivity}

Figure 2 shows variation of ionic conductivity of PVdF(HFP)-PMMA-NaI polymer blend electrolyte system. It is observed that [PVdF(HFP) (80 wt $\%)$-PMMA (20 wt $\%)$ ] $(20 \mathrm{wt} \%)-[\mathrm{NaI}(1.0 \mathrm{M})](80 \mathrm{wt} \%)$ composition of polymer blend electrolytes having free-standing film exhibits maximum conductivity of about $1.67 \times 10^{-2} \mathrm{~S} \mathrm{~cm}^{-1}$ at room temperature. They are very much suitable for device fabrication. The maximum conductivity is due to the proper PVdF(HFP)-PMMA polymer blend and salt interaction. Higher conductivity in polymer electrolyte system could be attributed to the higher amorphicity due to steric hindrance.

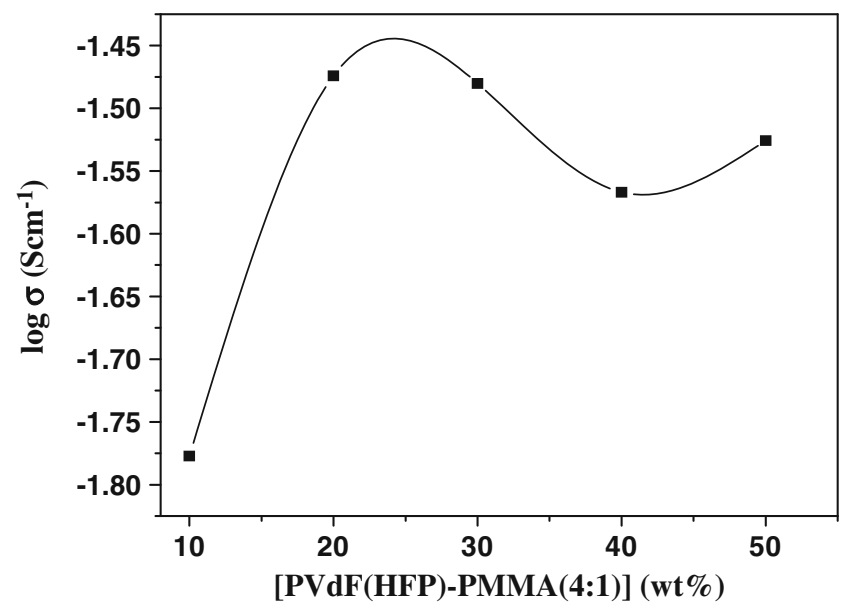

Figure 2. Variation of ionic conductivity of blend polymer electrolyte PVdF(HFP)-PMMA-NaI as a function of different weight percent of $[\mathrm{PVdF}(\mathrm{HFP})-\mathrm{PMMA}](4: 1 \mathrm{wt} \%)$ polymer blend concentration.

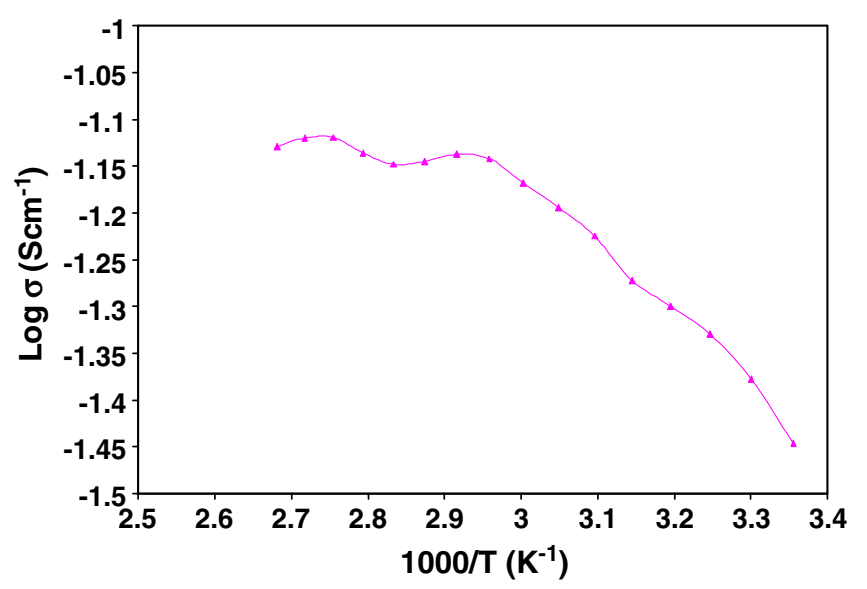

Figure 3. Variation of ionic conductivity of blend polymer electrolyte [PVdF(HFP)-PMMA(80:20)] (20 wt\%)-[NaI(1M)] $(80 \mathrm{wt} \%)$ as a function of different temperatures.

Higher amorphicity provides mobile $\mathrm{Na}^{+}$ion more free volume giving rise to higher conductivity of the electrolyte system.

\subsection{Temperature dependence conductivity}

Figure 3 shows temperature dependent ionic conductivity of polymer electrolytes system. From the plot it is evident that as the temperature increases the ionic conductivity also increases for the complex systems. The increase in conductivity with temperature may be due to the decrease in viscosity and hence increased chain flexibility (Michael et al 1997). The conductivity pattern shows almost Arrhenius behaviour up to $70{ }^{\circ} \mathrm{C}$ which can be expressed as

$$
\sigma=\sigma_{0} \exp \left(-E_{\mathrm{a}} / k T\right),
$$


where $\sigma_{0}$ is the pre-exponential factor, $E_{\mathrm{a}}$ the activation energy and $T$ the absolute temperature in Kelvin scale. The activation energy is found to be of the order of $0.06 \mathrm{eV}$ in polymer electrolyte system which has been calculated by fitting the curve in lower temperature region up to $70{ }^{\circ} \mathrm{C}$. The variation in ionic conductivity with temperature has been explained in terms of segmental motion that results in an increasing free volume of the sample and hence the motion of ionic charge. The amorphous nature of polymer blend provides a greater free volume of the system upon increasing the temperature (Tsunemi et al 1983). Thus the segmental motion either permits the ions from one site to another or provides the pathway for ions to move. This inter-chain or intra-chain ion movements are responsible for high ionic conductivity.

\subsection{Dielectric analysis}

Figures 4(a) and (b) show dielectric constant $\left(\varepsilon^{\prime}\right)$ and dielectric loss $\left(\varepsilon^{\prime \prime}\right)$ as a function of frequency at various temperatures for polymer blend electrolytes $[\mathrm{PVdF}(\mathrm{HFP})$ $(80 \mathrm{wt} \%)$ - PMMA (20 wt $\%)](20 \mathrm{wt} \%)-[\mathrm{NaI}(1.0 \mathrm{M})]$ $(80 \mathrm{wt} \%)$ system. Both the dielectric constant and dielectric loss part increase with decreasing frequency. This is attributed to the high contribution of charge accumulation at the electrode-electrolytes interfaces (Baskaran et al 2004). At higher frequencies the periodic reversal of the electric field occurs so fast that there is no excess ion diffusion in the direction of the field. Hence the polarization due to charge accumulation decreases and results in a decrease in both the dielectric constant and dielectric loss. The increase in the
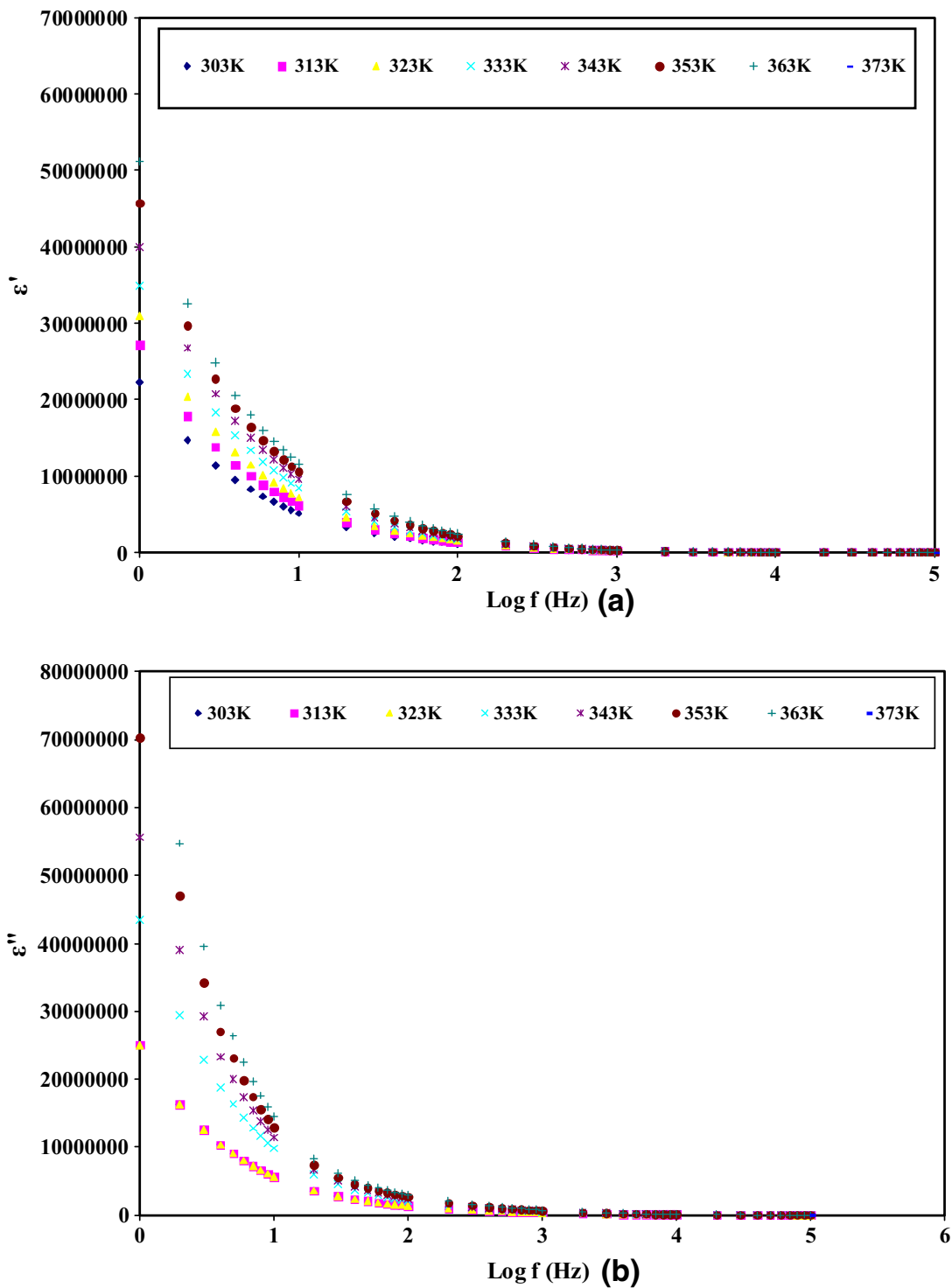

Figure 4. Variation of (a) dielectric constant; and (b) dielectric loss of polymer blend electrolyte system [PVdF(HFP)-PMMA (80:20)] (20 wt\%)-[NaI (1M)] (80 wt\%) at different frequencies. 
dielectric constant and dielectric loss with temperature can be attributed to the increase in charge carrier density due to the increase in dissociation of ion aggregates.

\subsection{Modulus spectra}

Figures 5(a) and (b) show the real part $\left(M^{\prime}\right)$ and imaginary part $\left(M^{\prime \prime}\right)$ of electrical modulus as a function of frequency at various temperatures for polymer blend electrolytes. Both $M^{\prime}$ and $M^{\prime \prime}$ are observed to increase in the high frequency region and give a long tail at lower frequencies. The peaks in the modulus formalism at high frequencies show that the polymer electrolytes films are ionic conductors. The peak curve at higher frequencies may be due to bulk effect. It is observed from the plots that $M^{\prime}$ and $M^{\prime \prime}$ decrease towards low frequen- cies. This is due to the electrode polarization phenomenon which makes a negligible contribution. The plots that show long tails at low frequencies are probably due to their large capacitance values associated with the electrodes.

\subsection{Conductance spectra}

The conductance spectra for $[\mathrm{PVdF}(\mathrm{HFP})(80 \mathrm{wt} \%)-$ PMMA (20 wt $\%)](20 \mathrm{wt} \%)$ - [NaI (1.0 M)] (80 wt \%) polymer blend electrolytes with different temperatures is shown in figure 6. The spectra consist of two regions, a low frequency dispersive region due to electrode-electrolyte interfacial phenomena and the plateau representing the d.c. conductivity. As the frequency decreases, more and more charge accumulation occurs at the electrode-electrolyte interface
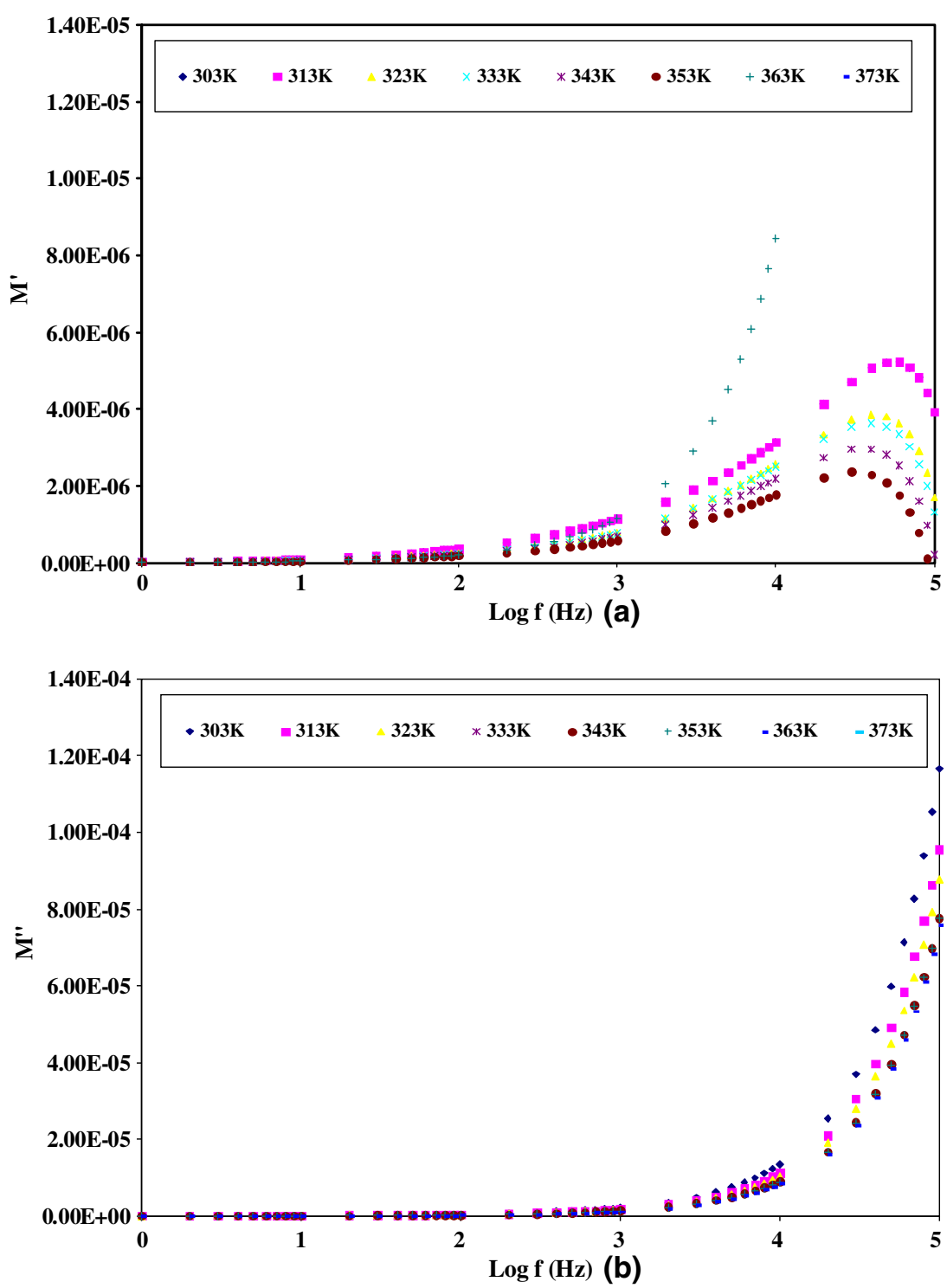

Figure 5. Variation of (a) real part and (b) imaginary part of electrical modulus for [PVdF(HFP)-PMMA (80:20)] (20 wt $\%$ )-[NaI (1M)] (80 wt \%) based polymer blend electrolyte system at different frequencies. 


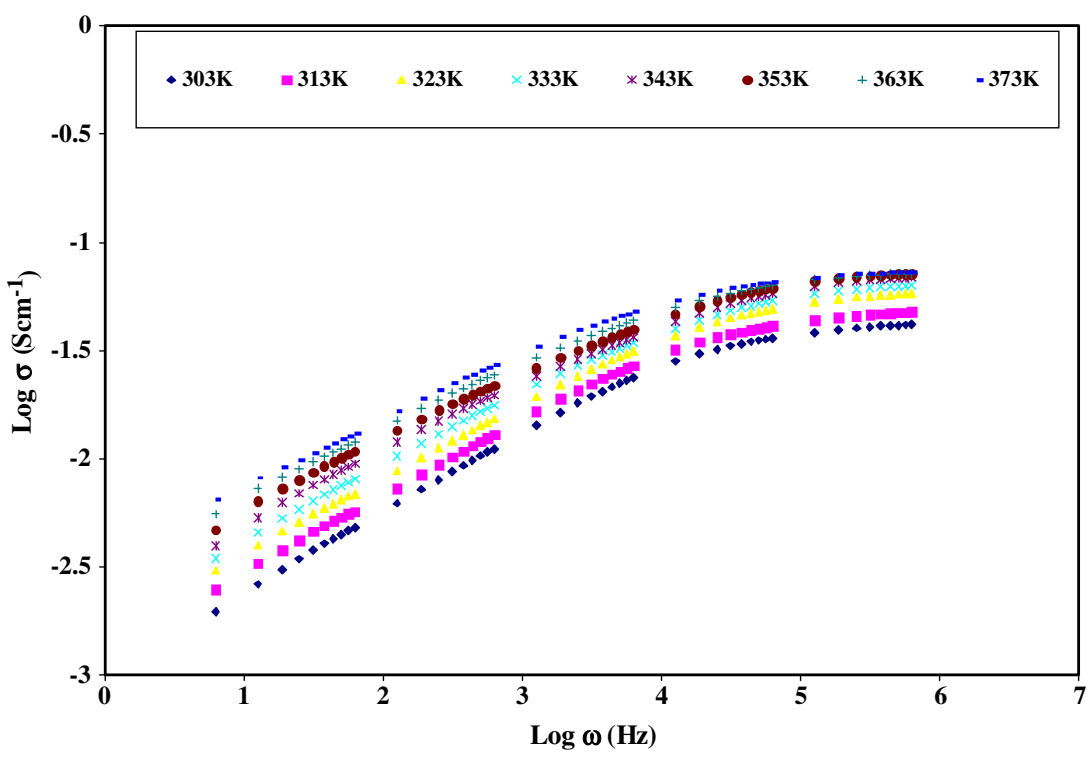

Figure 6. Variation of ionic conductivity for polymer blend electrolyte system [PVdF(HFP)-PMMA (80:20)] (20 wt\%)-[NaI (1M)] (80 wt\%) at different frequencies.

which leads to decrease in number of mobile ions and eventually to a drop in conductivity at low frequency. In high frequency region, the mobility of charge carriers is high and hence the conductivity increases with frequency (Ramesh and Arof 2001). It has been observed that the d.c. conductivity increases with temperature which suggests that the free volume around the polymer chain causes the mobility of ions and polymer segments (Miyamoto and Shibayama 1973).

\section{Conclusions}

The polymer blend electrolytes PVdF(HFP)-PMMA-1M $\mathrm{NaI}$ with different compositions have been prepared by solution cast technique. The highest conductivity, $\sigma=1.67 \times$ $10^{-2} \mathrm{~S} \mathrm{~cm} \mathrm{~cm}^{-1}$, at room temperature is obtained for PVdF(HFP):PMMA(80:20) polymer blend system. XRD studies show complete complexation of the salts in the polymer blend system. The dielectric and a.c. conductivity of the sample was studied and it was found that the synthesized polymer blend electrolyte material is suitable having acceptable properties for its application in energy storage/conversion devices like batteries, supercapacitor, fuel cell, solar cell etc. The polymeric system under present investigation is a very promising material for its application as electrolyte materials particularly in sodium batteries by offering ionic conductivity of the order of $10^{-2} \mathrm{~S} \mathrm{~cm}^{-1}$.

\section{Acknowledgements}

The authors are grateful to the Department of Science and Technology, Government of India, for providing financial support through the grant-in-aid for scientific research (grant sanction no.: SR/FTP/PS-02/2007). We are also thankful to UGC-DAE Consortium for Scientific Research, Indore, for providing their XRD facilities to characterize polymeric systems.

\section{References}

Agrawal R C and Pandey G P 2008 J. Phys.: Appl. Phys. 41223001

Baskaran R, Selvasekarapandian S, Hirankumar G and Bhuvaneswari M S 2004 Ionics 10129

Baskaran R, Selvasekarapandian S, Kuwata N, Kawamury Y and Hattori T 2006 Solid State Ionics 1772679

Berthier C, Gorecki W, Miner M, Armand M B, Chabagno J M and Rigand D 1989 Solid State Ionics 36165

Bruce P G and Gray F M 1995 in Solid state electrochemistry (eds) P G Bruce (Cambridge: Cambridge University Press) pp 119-162

Choi N S, Lee Y G, Park J K and Ko J M 2001 Electrochem. Acta 461581

Deepa M, Sharma N, Agnihotry S A and Chandra R 2002 J. Mater. Sci. 371759

Fenton D E, Parker J M and Wright P V 1973 Polymer 14589

Gray F M 1991 in Solid polymer electrolytes: Fundamentals and technological applications (eds) F M Gray (New York: VCH Publisher, Inc.) pp 21-30

Hunter C C and Ingram M D 1984 Solid State Ionics 1431

Hwang Y J, Jeong S K, Nahm K S and Stephan A M 2007 Eur. Polym. J. $\mathbf{4 3} 65$

Iijima T, Toyoguchi Y and Eda N 1985 Denki Kogaku 53619

Kim J S, Ahn H J, Kim I P, Kim K W, Ahn J H, Park C W and Ryu H S 2008 J. Solid State Electrochem. 12861

Lee C, Kim J H and Bae J Y 2003 Polymer 447143

Lee Y G and Park J K 2000 J. Power Sources $\mathbf{9 7 / 9 8} 616$

Leo C J, Subba Rao G V and Chowwdari B V R 2002 Solid State Ion. 148159

Michael M S, Jacob M M E, Prabaharan S R S and Radhakrishna S 1997 Solid State Ionics 98167

Miyamoto T and Shibayama K 1973 J. Appl. Phys. 537244

Rajendran S and Sivakumar P 2008 Physica B403 509 
Rajendran S, Prabu M R and Rani M U 2008 J. Power Sources 180 880

Rajendran S, Shanthi Bana V and Ramesh Prabhu M 2010 Ionics 1627

Ramesh S and Arof A K 2001 Mater. Sci. Eng. B85 11

Ramesh S, Winie T and Arof A K 2007 Eur. Polym. J. 431963

Saikia D and Kumar A 2004 Electrochim. Acta 492581

Sheldon M H, Glasse M D, Latham R J and Linfort R G 1989 J. Solid State Ionics $\mathbf{3 4} 135$

Sreekanth T, Jaipal Reddy M, Ramalingaiah S and Subba Rao U V 1999 J. Power Sources 79105
Sreepathi Rao S, Jaibal Reddy M, Laxmi Narsaiah E and Subba Rao U V 1995 J. Mater. Sci. Eng. B33 173

Stephan A M, Nahm K S, Kulandainathan M A, Ravi G and Wilson J 2006 J. Appl. Electrochem. 361091

Subramania A, Sundram N T K and Kumar G V 2006 J. Power Sources 153177

Tsunemi K, Ohno H and Tsuchida E 1983 Electrochim. Acta 28833

Ulaganathan M and Rajendran S 2010 Ionics 16515

Wang J, Yang J, Nuli Y and Holze R 2007 Electrochem. Commun. 931 